\title{
IMPROVING BUSINESS PROCESSES WITH RFID TECHNOLOGY
}

\author{
RAKIC-SKOKOVIC, M.; OSTOJIC, G.; LAZAREVIC, M. \& \\ STANKOVSKI, S.
}

Abstract: The actual and potential uses of RFID are wide-ranging and diverse. While many organizations are adopting RFID by force of mandate, even more of them are seeking ways to use the technology to improve their business processes. Implementation of the RFID technology, in an existing parking lot access control system in city of Novi Sad, has given benefits to all interest parts (the Parking Operator, parking place users and parking collectors).

Key words: RFID, business, processes, parking
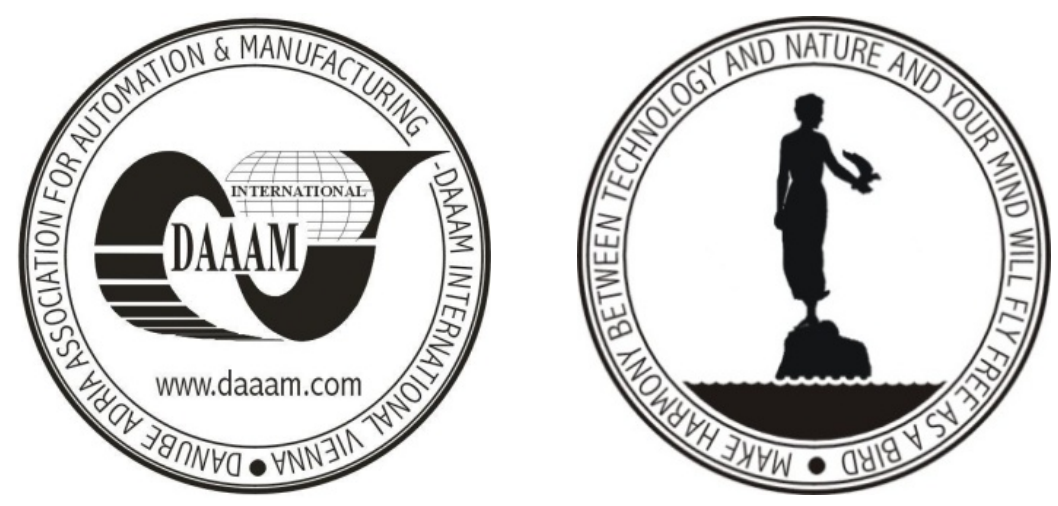

Authors' data: M.Sc. Rakic-Skokovic, M[arija]; PhD. Ostojic, G[ordana]; M.Sc. Lazarevic, M[ilovan]; PhD. Stankovski, S[tevan], Faculty of Technical Sciences Novi Sad, Trg D. Obradovica 6, 21000 Novi Sad, Republic of Serbia, marija@iis.ns.ac.yu,goca@uns.ac.rs, laza@iis.ns.ac.yu, stevan@uns.ac.rs

This Publication has to be referred as: Rakic-Skokovic, M[arija]; Ostojic, G[ordana]; Lazarevic, M[ilovan] \& Stankovski, S[tevan] (2009). Improving Business Processes with RFID Technology, Chapter 18 in DAAAM International Scientific Book 2009, pp. 161-168, B. Katalinic (Ed.), Published by DAAAM International, ISBN 978-3-901509-69-8, ISSN 1726-9687, Vienna, Austria

DOI: 10.2507/daaam.scibook.2009.18 